Revista Iberoamericana, Vol. LXXIII, Núm. 220, Julio-Septiembre 2007, 541-561

\title{
POÉTICAS DEL CONFLICTO ANDINO
}

POR

\author{
Elizabeth Monasterios P. \\ University of Pittsburgh
}

\begin{abstract}
Yo creía hasta ahora que todas las cosas del universo eran, inevitablemente, padres o hijos. Pero he aquí que mi dolor de hoy no es padre ni es hijo. Le falta espalda para anochecer, tanto como le sobra pecho para amanecer...

César Vallejo, 1923-1929

En la rebelión he aprendido que la lucha verdadera no había sido de unas cuantas personas, sino la causa había sido de millones y millones de indígenas, en eso había estado la riqueza; levantarse en forma comunitaria y autóctona, con su propio pensamiento filosófico...
\end{abstract}

Felipe Quispe, el Mallku, 2000

Posiblemente uno de los problemas menos resueltos en relación al estudio de la poesía sea entender por qué el campo poético ${ }^{1}$ no ha constituido, hasta ahora, materia de reflexión crítica en torno a los problemas que atañen a la literatura latinoamericana. Desde una perspectiva opuesta, muchos pensarán que la poesía no puede ni debe asumir tales responsabilidades, ya que los poemas no son (no deberían ser) capital cultural susceptible a intercambio en nombre de la teoría y el mercado académico. Así puede resumirse la contienda que se libra entre minorías que leen y producen poesía. Mi propósito al escribir este artículo no es ignorar la contienda sino más bien pensar fuera de ella, porque sospecho que a ambas partes les asiste razón. Ambas están tocadas por el escándalo semántico que

\footnotetext{
${ }^{1}$ La noción de campo, cuya inspiración proviene de Pierre Bourdieu, es aquí utilizada en sentido metodológico: apunta al señalamiento de un campo de fuerzas y luchas que poseen su propia lógica pero que nunca llegan a autonomizarse por completo. En este marco de definición el poema surge como un desbordamiento de sentidos que, contrariamente a lo que suele pensarse, no se resuelven en un mundo aparte, o en relación a referencialidades que sólo existen en la emotividad del poeta. $\mathrm{Al}$ contrario, un poema provoca incrementos de conciencia y diálogo intenso con el mundo que asumimos como real.
} 
produce la creación poética y provoca caos en el orden convencional del pensamiento; como si algo inherente a ella tuviera la capacidad de convertir palabras ordinarias en discursos perturbadores. Alquimia verbal sin duda, que bien podría hacerse extensiva a otros órdenes de la actividad humana, pero para eso tendríamos que conocer el proceso que la hace posible. Y eso ya es complicado, porque si algo ha quedado fuera de la comprensión de nuestra época ha sido precisamente una conciencia del proceso de creación poética. Eugenio Montale tenía razón cuando afirmaba que la poesía “es algo que conocemos muy poco" (214).

Tan poco es el conocimiento que de ella tenemos, que en el panorama crítico actual el campo poético no sólo no ha hablado todavía, sino que, con pocas excepciones, no ha tenido ingreso legítimo a la república de la crítica. Congresos, libros y mercado de trabajo confabulan para que la creación poética, junto a quienes la producen y a quienes la estudian, ocupe un sitio de marginalidad respecto al estrellato de los discursos fuertes, cada vez menos receptivos a los procesos de innovación semántica que genera la poesía. Teóricamente, persiste incluso en los lectores de poesía un criterio a priori que señala al lenguaje del poema como puramente emotivo por no ofrecer ningún esclarecimiento sobre el mundo real. Percepciones de esta naturaleza restringen el lenguaje del poema a una racionalidad intimista que lo señala como insuficiente para interactuar con la realidad, menos aún con criterios de historicidad. En las últimas décadas fueron los mismos poetas quienes percibieron el confinamiento al que iba siendo relegado el discurso poético. "El poeta ha dejado de ser la voz de su tribu,” sentenció alguna vez José Emilio Pacheco, recordándonos además que nuestra época ha convertido la poesía en un conjunto de "piruetitas verbales, suspirillos dolorosos" que nada pueden frente a una historia que hace tiempo “nos dejó hablando solos” (Tarde 78, 106, 76). También refiriéndose a la poesía y muy concretamente a la amenaza “post” de su posible desaparición, Octavio Paz insistió, ya hacia el final de sus días, en que "no vivimos el fin de la poesía, como han dicho algunos, sino de una tradición poética que se inició con los grandes románticos, alcanzó su apogeo con los simbolistas y su fascinante crepúsculo con las vanguardias de nuestro siglo. Otro arte amanece” (7-8).

Tanto en los versos de Pacheco como en las palabras de Paz puede apreciarse hasta qué punto esa marginalidad a la que se ha ido relegando a la poesía ha producido una percepción de su final. Pacheco, seguramente uno de los poetas más lúcidos de fines del siglo xx, tiende a la desolación. Sus libros ofrecen visiones apocalípticas porque en ellos el debilitamiento de la palabra poética llega acompañado del desastre que trae consigo el triunfo del tiempo histórico de la modernidad occidental. Por eso cuando vuelve la mirada hacia el hacer poético no puede sino registrar horror y dolor:

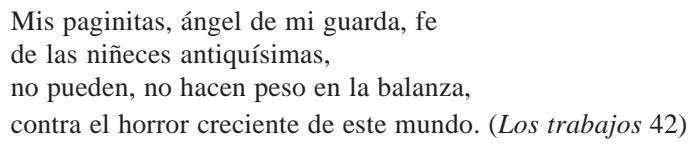

Incansablemente Pacheco se pregunta “y en dónde yace la esperanza, de dónde va a levantarse el día que sepulte la noche nuestra interminable, doliendo”. Pregunta que nunca tendrá respuesta, que será siempre mensaje vertido en una botella lanzada al mar, que está 
lleno de basura. En contraste, Paz ofrece una visión reconstructora y por eso mismo propositiva. En principio, relaciona ese sentido de “final” que parece amenazar a la poesía con el fin de las dos ideas que han constituido la modernidad: la idea de que el tiempo es una sucesión lineal orientada hacia el futuro y el progreso; y la noción de que el cambio, la revolución y la ruptura son las formas privilegiadas de la sucesión temporal. Estos modelos históricos y no la poesía misma son los que, en opinión de Paz, han llegado a su fin. Esto lo lleva a concluir que "otro arte amanece". Un arte llamado a evitar las faltas y errores del anterior, que Paz caracteriza como una extraordinaria capacidad para desoír esas realidades enterradas, poco disponibles al ojo común, pero que constituyen la materia misma de la que está hecha la poesía:

Si, como creo, nace un nuevo pensamiento político, sus creadores tendrán que oír la otra voz. Fue inoída por los ideólogos y revolucionarios de nuestro siglo y eso explica, en parte al menos, el gran fracaso de sus proyectos. Sería desastroso que la nueva filosofía política ignorase esas realidades ocultadas y enterradas por el hombre moderno. La función de la poesía durante los dos últimos siglos ha sido recordarnos la existencia de esas realidades; la función de la poesía de mañana no podrá ser distinta. (135)

Es evidente que el llamado de Paz a escuchar la otra voz es un llamado a escuchar esas perturbaciones que produce la creación poética y que tienen la capacidad de provocar caos en el orden convencional del pensamiento y “escándalo en la modernidad”. Lo que llama la atención es la manera en que el último Paz relaciona el proceso de creación poética con el pensamiento político, llegando incluso a formular la urgencia de una filosofía política, como si poética, filosofía y política no fueran discursividades tradicionalmente reñidas entre sí. Pero el profundo malestar intelectual de nuestra época y los formidables sacudimientos históricos que la caracterizan llevan a Paz a postular un diálogo entre ellas. Queda así la creación poética definida al interior de un campo de fuerzas y luchas que poseen su propia lógica y que, no obstante, están llamadas a dialogar. Desafortunadamente Paz no se detiene en ese diálogo; le interesa más bien destacar que de él podría surgir la otra voz, es decir, la presencia de realidades ocultas y enterradas por la modernidad pero reveladas por la poesía:

Un poema puede ser moderno por sus temas, su lenguaje y su forma, pero por su naturaleza profunda es una voz antimoderna. El poema expresa realidades ajenas a la modernidad, mundos y estratos psíquicos que no sólo son más antiguos sino impermeables a los cambios de la historia... aunque atada a un suelo y a una historia, [la poesía] siempre se ha abierto, en cada una de sus manifestaciones, a un más allá transhistórico. No aludo a un más allá religioso: hablo de la percepción del otro lado de la realidad. (133)

Y ya hacia el final de su texto remata estas ideas observando que "la poesía es el antídoto de la técnica y del mercado. A esto se reduce lo que podría ser, en nuestro tiempo y en el que llega, la función de la poesía” (138-9). Muchas preguntas asaltan al lector después de leer las últimas páginas de La otra voz, y siempre son críticas: ¿cómo resuelve Paz la aparente contradicción de un arte simultáneamente atado y desatado de un suelo y de una historia? ¿Por qué, en una época supuestamente postideológica, la poesía está llamada a ser "antídoto de la técnica y del mercado”? ¿Acaso no fueron ya antídoto del 
mercado las poéticas de César Vallejo, Alejandra Pizarnik, José Emilio Pacheco o Juan Luis Martínez, sólo para citar casos muy concretos? ¿Dónde radica la novedad del "nuevo arte” que postula Paz? Bien vistas las cosas, esa novedad podría derivar precisamente del diálogo que Paz plantea (pero no desarrolla) entre poética, política y filosofía. Diálogo impensable desde una racionalidad moderna que las diferencia y separa, pero suficiente para que se configure en las sociedades actuales un campo poético distinto, renovado, capaz de pertenecer a tres universos distintos del saber: el mundo de la creación poética, que implica peligro, riesgos en el pensamiento; el mundo de la política o sabiduría estratégica, que produce efectos concretos en las relaciones sociales; y el mundo del rigor filosófico, que exige un salir de sí mismo para atreverse a pensar más.

A su manera, las vanguardias y neovanguardias de nuestro siglo transitaron por estos mundos, pero los transitaron separadamente. Pablo Neruda, Ernesto Cardenal o Nicolás Guillén, privilegiando el mundo de la fuerza política; Vicente Huidobro, Juan Luis Martínez o Alejandra Pizarnik, el de la creación poética; Borges el de la filosofía. Pocos han sido los poetas y escritores que abiertamente han cifrado el proceso de creación poética desde la convergencia de estos tres mundos, probablemente porque este tipo de alianzas más que en una obra individual cristaliza en procesos artísticos de largo recorrido que forjan el surgimiento de una conciencia poética capaz de expresar el espíritu histórico de una época. Este artículo propone que la región andina, precisamente por estar ella misma inserta en una convergencia de mundos y temporalidades distintas y enfrentadas, registra el surgimiento de una conciencia poética que además de poseer contornos propios y originales, ha permitido la articulación de un pensamiento teórico-crítico que ya empieza a ser escuchado y con el que la crítica académica metropolitana tendrá que dialogar en algún momento. Una manera de estudiar el desarrollo de este proceso poético es a través de algunas de sus apachetas (cumbres) más representativas: los peruanos César Vallejo (1892-1938) y José María Arguedas (1911-1969) y el hasta hace poco desconocido poeta boliviano Jaime Saenz (1921-1986), uno de los escritores más importantes de la literatura boliviana contemporánea y el que más influencia está ejerciendo tanto en el desarrollo del proceso cultural de este país como en la comprensión de ese intrincado, todavía poco estudiado fenómeno que fue la vanguardia andina, cuyos representantes más notables son Arturo Borda (1883-1953) y Gamaliel Churata (1897-1969). ${ }^{2}$

Si algo caracteriza a estos tres escritores es precisamente la convergencia de mundos que se da en sus obras y que explica por qué ha sido tan difícil rotularlas con etiquetas

\footnotetext{
${ }^{2}$ La inmensa y conmovedora obra de Saenz empezó a publicarse a mediados de los años cincuenta (El escalpelo, 1955) y continuó ininterrumpidamente hasta el final de sus días, en 1986. A partir de esa fecha, empezó a conocerse una copiosa obra inédita que hasta el momento no se ha agotado. Más conocido como poeta, Sáenz fue también un extraordinario narrador, ensayista, artista plástico, inventor y relojero, pero sobre todo fue el creador de una gramática poética premeditadamente anclada en los rincones de la andina ciudad de La Paz. El principio que guía su obra es la idea de que el escritor, en cuanto creador, no debe perder nunca contacto con su realidad: "Guay del que pierda contacto con la realidad! Debe mantenerlo a toda costa, para sacar de ella la gran poesía, el gran canto a la vida. De la propia realidad, fluye la otra la mágica, que al mismo tiempo es satánica y divina” (López Muñoz 1). Para un estudio detenido de la obra saenciana véanse Antezana, Ensayos y lecturas; Wiethücher y Paz Soldán; y Monasterios.
} 
reconocibles por un canon que veía con malos ojos la coexistencia de la diferencia, sea ésta de origen ético, estético o político. Ha sido más cómodo referirse a Vallejo como a un poeta marxista enfrascado en una poética del dolor; expulsar a Arguedas del boom latinoamericano y confinarlo a la literatura etnográfica; neutralizar la provocación de Saenz en universos autorreferenciales provistos de carga fascista. Pero nada conjuró los terremotos culturales que estos autores y sus obras estaban desatando y que impidieron que en los Andes el siglo xx finalizara en un panorama lavado de neoliberalismo. Fueron esos terremotos culturales los actos epistemológicos que, desde la región andina, articularon un nuevo campo poético en el horizonte cultural. Para ello, obligaron al discurso poético a enunciarse al margen de las dos ideas que habían constituido la modernidad: la idea de que el tiempo es una sucesión lineal orientada hacia el futuro y el progreso, y la noción de que el cambio, la revolución y la ruptura son las formas privilegiadas de la sucesión temporal. Vallejo, Arguedas y Saenz escriben desde temporalidades y racionalidades distintas. Sus libros son verdaderas provocaciones porque destruyen esa percepción simplista de la realidad que forja la costumbre y nos dejan perplejos, sin palabras. Por eso no los entendemos, pero también por eso nos empujan a pensar más y a tomar conciencia de los laberintos que en los Andes frecuenta el proceso de creación poética.

¿Por Qué Vallejo nos Deja sin Palabras?

La obra de Vallejo en su conjunto tiene la capacidad de dejarnos sin palabras, pero para que esta catástrofe preciosa quede explícita al lector de estas páginas voy a detenerme en el comentario de un solo poema, "Voy a hablar de la esperanza", escrito entre 19231929 e incluido en Poemas en prosa (1939). ${ }^{3}$ Se trata de una composición que, muy al estilo de Vallejo, destruye el sentido común y detiene el ejercicio convencional del pensamiento. Y no porque el lenguaje (simple, cotidiano) escape a la comprensión, sino más bien porque nuestra comprensión no logra acceder a la lógica de esa simplicidad. "Voy a hablar de la esperanza" pone en marcha una estructura de paradoja que aparentemente cancela la posibilidad de una interpretación:

Yo no sufro este dolor como César Vallejo. Yo no me duelo ahora como artista, como hombre ni como simple ser vivo siquiera. Yo no sufro este dolor como católico, como mahometano ni como ateo. Hoy sufro solamente. Si no me llamase César Vallejo, también sufriría este mismo dolor. Si no fuera artista, también lo sufriría. Si no fuese hombre ni ser vivo siquiera, también lo sufriría. Si no fuese católico, ateo ni mahometano, también lo sufriría. Hoy sufro desde más abajo. Hoy sufro solamente.

Me duelo ahora sin explicaciones. Mi dolor es tan hondo que no tuvo ya causa ni carece de causa. ¿Qué sería su causa? ¿Dónde está aquello tan importante, que dejase de ser su

\footnotetext{
${ }^{3}$ Georgette de Vallejo afirma que la colección hoy conocida como Poemas en prosa apareció por primera vez en la edición de 1939 de Poemas humanos, que también incluía España aparta de mí este caliz. Al respecto, consultar Obra poética completa (Lima: Moncloa, 1968). Esta edición fue dirigida por Georgette de Vallejo, prologada por Américo Ferrari y revisada por Abelardo Oquendo. Casa de las Américas la reprodujo en 1970 con prólogo de Roberto Fernández Retamar, y Mosca Azul Editores en 1974, con anotaciones biográficas de Georgette de Vallejo.
} 
causa? Nada es su causa; nada ha podido dejar de ser su causa. ¿A qué ha nacido este dolor, por sí mismo? Mi dolor es del viento del norte y del viento del sur, como esos huevos neutros que algunas aves raras ponen al viento. Si hubiera muerto mi novia, mi dolor sería igual. Si me hubieran cortado el cuello de raíz, mi dolor sería igual. Si la vida fuese, en fin, de otro modo, mi dolor sería igual. Hoy sufro desde más arriba. Hoy sufro solamente.

Miro el dolor del hambriendo y veo que su hambre anda tan lejos de mi sufrimiento, que de quedarme ayuno hasta morir, saldría siempre de mi tumba una brizna de yerba al menos. Lo mismo el enamorado. ¡Qué sangre la suya más engendrada, para la mía sin fuente ni consumo!

Yo creía hasta ahora que todas las cosas del universo eran, inevitablemente, padres e hijos. Pero he aquí que mi dolor de hoy no es padre ni es hijo. Le falta espalda para anochecer, tanto como le sobra pecho para amanecer, y si lo pusiesen en la estancia oscura, no daría luz y si lo pusiesen en una estancia luminosa no echaría sombra. Hoy sufro suceda lo que suceda. Hoy sufro solamente.

Si bien es cierto que este poema (como en general la obra vallejiana) nació en el mayor vacío, y pasó ignorado por las calles de Lima, también es cierto que entre sus contemporáneos encontró al que sería su mejor lector: José Carlos Mariátegui, sin cuyas lecturas sería impensable la crítica vallejiana de hoy día. Fue Mariátegui quien entendió, desde el principio, la pulsión andina que atravesaba la obra de Vallejo y que no se dejaba encapsular en etiquetas folkloristas o hundir en la tradición. En opinión de Mariátegui, el sentimiento indígena en Vallejo es empresa metafísica, y está punzada por un dolor de tres siglos ("El proceso de la literatura”, Siete ensayos... 284-7).

Nadie como William Rowe supo instrumentalizar esta lectura de Mariátegui para dialogar, desde la crítica cultural, con un poema como "Voy a hablar de la esperanza" (99124). Asumiendo que se trata de uno de los poemas claves del siglo xx, Rowe aborda directamente el problema de interpretación que plantea el texto. "Si hay mil maneras de significar el dolor, Vallejo las evita todas”, escribe este crítico, y en seguida va mostrándonos cómo el poema de Vallejo va paralizando todas las estructuras clásicas del conocimiento. Con ellas, queda también paralizado el orden verbal (el español y su estructura de significación) y cultural (la cultura blanco-criolla peruana) que las hacían inteligibles para nosotros. Este proceso lleva a Rowe a concluir que el poema resiste a la interpretación porque su espacio de enunciación es percibido como espacio vacío. Es a ese vacío epistemológico al que la lectura no puede llegar, porque ni la lengua que manejamos (español) ni su campo de significación son suficientes para acceder a aquello que está pasando en el poema y que no deriva de una situación en particular. Al contrario, parece ser el desborde de una acumulación de situaciones. El "dolor” que revela el poema carece de causa ubicable, no está en un sitio determinado ni refiere a un hecho concreto. Al contrario, está en todos los lugares al mismo tiempo, habita todos los espacios, y toca todas las instancias de la vida. Esta desquiciante situación de simultaneidad es lo que no encuentra referente en nuestra conciencia, más bien habituada a la linealidad de los acontecimientos y a la relación causa-efecto. De aquí que ninguna interpretación basada en la biografía del autor o en la primacía de un solo significante alcance para llegar a lo que pasa en los poemas de Vallejo, del mismo modo que ningún aspecto aislado de la 
historia del Perú es suficiente para abarcar su conflictividad social y cultural. Así propuestas las cosas, salta a la vista que los poemas de Vallejo no son, no pueden ser, enigmas sin solución o el colapso semántico puro y simple. Otra pertinencia y otras referencias están actuando en ellos, y el trabajo de Rowe las hace explícitas para nosotros. Para ello, lee el dolor de Vallejo en términos mariateguianos: como signo cultural, como síntoma de la esquizofrenia histórica que vive un país que, como el Perú, ha producido una modernidad desigual incapaz de incluir a todos los peruanos en un mismo tiempo histórico. Conviven conflictivamente en el Perú (y por extensión en la región andina) las más diversas temporalidades: la originaria premoderna; la colonial desterritorializadora; y la moderna, con sus infatigables ofertas de progreso. ${ }^{4}$ Rowe llega incluso a trazar un mapa de la socialización del dolor en el Perú que le sirve para localizar en la cultura peruana un origen colectivo del dolor: el aqoy phuti (dolor sin límite) que en los Andes produjo la Conquista y la muerte de Atahuallpa. Observa también que junto al aqoy phuti colectivo persiste en el Perú el dolor individual, inagotable, del mestizo, para quien no existe una comunidad compartida; y la moderna visión de un progreso prometedor pero inalcanzable. La importancia del trabajo de Rowe reside en que permite entender que la extrañeza de un poema como "Voy a hablar de la esperanza" reside en el hecho de estar enunciado desde la intersección de estos conflictos, es decir, simultáneamente desde el horror colonial, lo andino no-capitalista, lo mestizo sin acomodo y el imaginario occidental moderno. Tan desquiciante y desorientadora llega a ser la convivencia de esta multitemporalidad que su sola enunciación produce en el poema la sensación de un vacío epistemológico, tal vez por lo insoportable que resulta admitir que en los Andes el dolor no tiene posibilidades de trascendencia. Rowe concluye su ensayo subrayando que:

...frente a los discursos que racionalizan y escamotean el dolor y otras zonas involuntarias de la existencia Vallejo vocea y alborota... se une a Mariátegui y Arguedas en la investigación de las relaciones entre la política, el lenguaje y lo irracional. Todavía hay mucho que hacer. Sin embargo la poesía de Vallejo se ofrece como un experimento útil y una preparación para lo nuevo. (123-4)

Como antes Paz, Rowe también convoca el advenimiento de "lo nuevo” y sitúa el germen de esa novedad en el cruce del lenguaje con la política y lo irracional. Pero a diferencia de $\mathrm{Paz}$, que desde el sitio de las generalidades postula que la función de la poesía de mañana está llamada a oír la otra voz, Rowe le da a esa misma idea un anclaje históricocultural muy sugerente: en materia de reflexión crítica y producción de conocimiento, es mucho lo que pueden aportar poéticas que, arrancando del conflicto andino, encaran las distintas desarmonías que desata la modernidad.

\footnotetext{
${ }^{4}$ Recordemos que Mariátegui ya había sentado las bases para esta reflexión al observar que "en el Perú actual coexisten elementos de tres economías diferentes. Bajo el régimen de economía feudal nacido de la Conquista subsisten en la sierra algunos residuos vivos todavía de la economía comunista indígena. En la costa, sobre un suelo feudal, crece una economía burguesa que, por lo menos en su desarrollo mental, da la impresión de una economía retardada” (15).
} 
PoÉTICAS DEL CONFLICTO ANDINO

Si algo quedó definitivamente fuera de la modernidad en los Andes, fue el “problema” que planteaban las culturas y los sujetos andinos, a los que ni el indigenismo ni el nacionalismo pudieron legítimamente representar y menos aún incorporar a los proyectos de la nación criolla-mestiza. Vallejo vivió esta situación de manera radicalmente conflictiva. Si bien compartió la ideología de la vanguardia social que le era contemporánea (Haya de la Torre y Mariátegui), su entendimiento del mundo andino difícilmente actúa dentro de marcos indigenistas o marxistas exclusivamente. Hay en Vallejo un excedente de sentido que perturba y hace que sus poemas resulten incomprensibles, divorciados en definitiva de sentidos preconcebidos, en gran medida porque a su obra la cruza el impensado, hasta hoy día poco estudiado vanguardismo andino. ${ }^{5}$ Este proceso queda explícito en "Voy a hablar de la esperanza", donde, como observa Rowe, una contundente declaración personal desautoriza una interpretación únicamente basada en la épica comunista: "miro el dolor del hambriento y veo que su hambre anda tan lejos de mi sufrimiento”.

También desautorizada queda la posibilidad de interpretar el poema dentro de las coordenadas del indigenismo, ya que en ningún momento es abordado el tema del indio. Y sin embargo, desde su estructura formal, "Voy a hablar de la esperanza” pone en marcha modos andinos de expresión y organización espacial. Las cuatro partes que lo conforman reproducen a nivel textual el diseño cuatripartito o suyus que conformaban la geografía del Tawantinsuyu. Dentro de esta geografía, queda claramente expresada la idea de dos

${ }^{5}$ Por mucho tiempo la categoría misma de vanguardia andina fue inexistente. En los Andes, como en general en Latinoamérica, predominó el consenso continental que admitía como vanguardistas únicamente aquellas obras y aquellos autores que dialogaban con los ismos europeos. Esta unilateralidad del campo de acción vanguardista se rompió cuando José Emilio Pacheco propuso la antipoesía y la poesía conversacional como agentes propulsores de lo que él llamó "la otra vanguardia," definida como realista y no surrealista, y en deuda con la New Poetry norteamericana (“Notas...”). La irrupción de una vanguardia andina ensancha todavía más el horizonte conceptual vanguardista, ya que ahora se trata de obras y autores que -como Arturo Borda, Gamaliel Churata, y más tarde Saenz- asumen el reto vallejiano de "realizar un espíritu propio", y se dan a la tarea de desafiar la sensibilidad de toda una época con la irrupción de formas culturales andinas en sus obras. Producen así la insoportable, impensable convivencia de lo indígena marginal con lo irracional surrealista y lo político social. Estos “demoledores” del status quo de la modernidad proponen su escritura desde la posición del lari (el despojado de sentido, el huérfano de código social). Vivir como laris los ha abierto a la percepción de aspectos desconocidos de la realidad. De allí la sospecha que tiene Borda de que "seré en algo, no sé en qué, el primero y el único" (El loco 37), o la increíble lucidez de Churata para entender que "cualquier mestizaje es imposible, mas hay alguno impensable [...] es el del hispano y las lenguas aborígenes de América” (43). Como es de suponer, el estudio de la vanguardia andina es muy reciente y son pocos los trabajos críticos disponibles. A esto se suma la dificultad de acceso a la obra de Borda y Churata, cuyos textos mayores, El loco (póstumamente publicado en 1966) y El pez de oro (1957) respectivamente, no cuentan hasta la fecha con reediciones. Pero al margen de toda posible dificultad, son fundamentales, en relación a Churata, los aportes de Miguel Angel Huamán, Juan Zevallos, Gissela González Fernández, Manuel Pantigoso y Marco Thomas Bosshard. En relación a Borda destaca la reciente aparición de Hacia una historia crítica de la literatura boliviana, donde un equipo de investigadores de la Universidad Católica Boliviana propone la obra de Borda como eje articulador de la literatura de este país. 
territorialidades distintivas y recíprocas: un arriba y un abajo. Estas territorialidades o mitades, que en la historia andina constituyen la base de la sociabilidad entre comunidades, en el poema conforman zonas de dolor. Literalmente Vallejo nos dice primero: "Hoy sufro desde más abajo” y después: “Hoy sufro desde más arriba”. La terminología arriba-abajo, a primera vista desorientadora, empieza a adquirir lógica y sentido una vez que entran en funcionamiento los referentes andinos. Entendemos entonces que el dolor del poema es irreducible a la persona de César Vallejo porque atañe a la cultura y a la historia andina. Incluso la última parte del poema, francamente perturbadora, encuentra sitio y sentido desde una perspectiva andina:

Yo creía hasta ahora que todas las cosas del universo eran, inevitablemente, padres e hijos. Pero he aquí que mi dolor de hoy no es padre ni es hijo. Le falta espalda para anochecer, tanto como le sobra pecho para amanecer, y si lo pusiesen en la estancia oscura, no daría luz y si lo pusiesen en una estancia luminosa no echaría sombra. Hoy sufro suceda lo que suceda. Hoy sufro solamente.

Tanto los estudiosos del mundo andino como la realidad de las comunidades que todavía conservan formas andinas de vida nos enseñan que en los Andes los grupos humanos organizaban sus territorios en dos grandes mitades llamadas en quechua hanansaya (mitad de arriba) y hurinsaya (mitad de abajo). Estas mitades, que constituían núcleos de intercambio social, cultural y productivo, estaban reguladas por la autoridad de un Kuraka (cacique, señor) que era como su "padre”, y se dividían cada una en cinco ayllus menores o "ayllus hijos”. Tan funcional y productiva era esta dinámica territorial que de ella dependía el orden económico y cultural del Tahuantinsuyu (Platt 61-132).

Esta breve descripción de cómo estaba (y en muchos casos todavía está) organizada la territorialidad andina permite postular que en "Voy a hablar de la esperanza” Vallejo nos está confesando que él creía, hasta ahora, en la posibilidad de un orden andino de las cosas, pero la historia personal y colectiva que le tocó vivir le ha mostrado la inviabilidad y hasta la inexistencia de ese orden en el Perú. Es un orden que ha perdido espesor, que se ha vaciado, que no da sombra siquiera. Poética del despojo andino la de Vallejo, y al mismo tiempo proyecto estético que supo, como ningún otro de su tiempo, componer poesía desde otra epistemología, porque aun cuando los poemas están escritos en español, actualizan otra gramática y otro campo de significación. La paradoja es que en Vallejo la herida, por productiva que sea, es también un límite: forja la irrupción de una poética del conflicto andino pero no admite salidas. Concluyente, se impone el desgarrado vacío de un mundo que está allí, cuya pulsión Vallejo puede palpar, pero que ha perdido espesor, que se ha vaciado, que no da sombra siquiera. Tal vez por eso Rowe concluye uno de sus ensayos sobre Vallejo señalando que su poesía "se ofrece como un experimento útil y una preparación para lo nuevo,” pero “todavía hay mucho que hacer”.

\section{ARguedAS O DE CÓMO TRANSMITIR A LA PALABRA LA MATERIA DE LAS COSAS ANDINAS}

En el Perú, nadie como José María Arguedas transitó por las rutas abiertas por Vallejo y teorizadas por Mariátegui. En muchos sentidos su obra también sucumbe ante la herida viva de la realidad peruana, pero en muchos otros la supera y le da al conflicto andino una 
direccionalidad que antes no tenía. Tal vez por eso Antonio Melis sugiere que el proceso cultural andino tiene un momento de culminación en la obra de Arguedas, al que percibe como el auténtico heredero de Mariátegui (505).

La intensa y conmovedora obra arguediana arranca de los mismos conflictos que asolaron a Vallejo: una profunda crisis personal; otra, igualmente profunda, pero de alcance colectivo; y la experiencia de la modernidad como pobreza. Pero a diferencia de Vallejo, que encuentra modos (por más oscuros y difíciles que resulten) de expresar la conflictividad andina y recrear su epistemología, Arguedas parece no poder hacerlo. Toda su vida y toda su obra son una lucha por encontrar el modo, el lenguaje capaz de expresar apropiadamente esa conflictividad y esa epistemología. Persigue a Arguedas la idea de que él, como adulto, y el Perú como nación, han perdido vínculo con las cosas que podrían reconstruirlos y devolverles sombra, espesor... Donde mejor queda expresado este proyecto escritural es en su enigmática novela póstuma El zorro de arriba y el zorro de abajo, cuya escritura empezó en 1968, cuatro años después de haber traducido el manuscrito quechua del siglo xvi conocido como Runa yndio o Dioses y Hombres de Huarochirí. ${ }^{6}$ En el Primer Diario de esta novela Arguedas confiesa su dificultad para "recuperar el roto vínculo con todas las cosas", y significativamente agrega que "cuando ese vínculo se hacía intenso podía transmitir a la palabra la materia de las cosas” (11). Significativamente también, es el niño Arguedas el que a veces logra restituir ese vínculo que para el adulto ya se presenta como insalvable. Pero Arguedas no descansa, y en sus desesperados esfuerzos por restituir vínculos rotos advierte, como antes Vallejo, la imposibilidad de llegar a la intimidad andina a través de la estructura lógico-racional del castellano. Por eso le resulta difícil verter en lengua hispana referentes andinos:

No hace quince días que logré rascar la cabeza de un nionena (chancho) algo grande, en San Miguel de Obrajillo. Medio que quiso huir, pero la dicha de la rascada lo hizo detenerse; empezó a gruñir con delicia, luego (¡cuánto me cuesta encontrar los términos necesarios!) se derrumbó a pocos y, ya echado y con los ojos cerrados gemía dulcemente. La alta, la altísima cascada que baja desde la inalcanzable cumbre de rocas, cantaba en el gemido de ese nionena, en sus cerdas duras que se convirtieron en suaves; y el sol tibio... caldeado de plenitud, de hermosura...estaba mejor que en ninguna parte en el lenguaje del nionena, en su sueño delicioso. (12-3)

¿Cómo expresar semejante polifonía discursiva con un lenguaje que únicamente le concede voz al género humano? Claramente Arguedas está hablando desde una razón que concibe al mundo como un sitio en el que todo habla. Habla el agua, habla la cascada, la

\footnotetext{
${ }^{6}$ Esta ambivalencia en el título se debe a los distintos nombres que el manuscrito fue recibiendo. Originalmente compilado alrededor de 1608 por el padre Francisco de Ávila o por algún escriba a su cargo, fue conocido como Tratado y relación de los errores, falsos dioses y otras supersticiones y ritos diabólicos en que vivían antiguamente los indios de las provincias de Huarochirí, Mama y Chaclla y hoy también viven engañados con gran perdición de sus almas. En 1939 el traductor y editor alemán Hermann Trimborn propuso como título la primera línea del texto, Runa yndio niscap Machoncuna (Antepasados del pueblo llamados indios). Finalmente, cuando Arguedas tradujo el manuscrito original al español prefirió llamarlo Dioses y Hombres de Huarochirí: Narración quechua recogida por Francisco de Ávila [¿1598?].
} 
montaña, hablan los animales y habla, también, el ser humano. En un artículo sin precedentes en la crítica arguediana, Sara Castro-Klaren observa que esta capacidad que despliega el texto para descolocar la racionalidad moderna deriva del encuentro que tuvo Arguedas con las prácticas religiosas andinas insertas en el manuscrito de Huarochirí. La tesis de Castro-Klaren es que en su lectura y traducción de este manuscrito,

Arguedas encontró desplegados, en todo su poder, la sabiduría y los modos de conocer
de los antiguos cuyo mundo él había venerado a distancia, en la naturaleza y belleza
misma del lenguaje y la cultura quechua, y sobre todo en la conformación del reino de
lo sagrado. [...] Instintivamente, Arguedas había estado utilizando modos de conocimiento
chamánico para escribir. Pero [...] no había entendido realmente la naturaleza de los
poderes de los que se había estado alimentando hasta que leyó los textos chamánicos en
quechua. Los poetas de Huarochirí hacen evidente la poderosa relación de la palabra con
la institución de lo sagrado, así como también los vínculos del conocimiento con el afecto.
Esta revelación fue tan poderosa y sobrecogedora que tuvo que ser enterrada en una
incapacidad para escribirla. (30, 34)

Arguedas, siguiendo este argumento, difícilmente pudo manejar ese mostrarse de los modos andinos de conocer y, a partir de ellos, producir un texto coherente y terminado que, sin renunciar a los temas centrales de su obra, abarcara la provocación epistemológica que emergía de la cosmogonía de Huarochirí y que dejaba ver la materia de la que estaba hecha la sensibilidad andina: una geografía sacralizada con cerros, montañas y valles que copulan entre sí, manantiales que cantan, divinidades que encarnan en fenómenos naturales, seres humanos que se convierten en animales, zorros que hablan, hijos que nacen con anterioridad a sus padres, cópulas y sexualidades descomunales. ${ }^{7}$

Este perturbador encuentro con los modos de ser del mundo andino no pudo haber pasado por alto el poderoso correlato histórico que daba fuerza y sentido a la cosmogonía de Huarochirí. Arguedas tuvo que haber percibido que detrás de la desmesura de las imágenes quedaban plasmados los complejos procesos de inmigración y reacomodación pastoral de los distintos grupos preincaicos que ocuparon el territorio de Huarochirí y cuyas prácticas de parentesco dieron paso a lo que Frank Salomon llama "an ideology of affinal interdependence” (8). Arguedas, que precisamente mientras escribía El zorro de arriba y el zorro de abajo luchaba por comprender el horror migratorio de Chimbote (que remite al proceso de industrialización capitalista de la costa peruana), encontró en esta "ideology of affinal interdependence" un diagnóstico andino para la realidad del puerto pesquero. Los poetas de Huarochirí le habían mostrado que el fenómeno migratorio y sus secuelas expansionistas y transculturadoras eran experiencias que el mundo andino no sólo conocía muy bien, sino que había sabido resolver favorablemente mediante prácticas cúlticas de parentesco y reciprocidad. Bastaba observar los movimientos migratorios en Huarochirí para darse cuenta de que la presencia de invasores extranjeros había sido

\footnotetext{
${ }^{7}$ Vale la pena subrayar que esta materia de la que están hechas las cosas andinas difícilmente puede entenderse como irracional o tributaria de un realismo mágico. Hacerlo implicaría la imposición de modelos culturales ajenos a la sensibilidad del mundo que se quiere estudiar. Así lo entendieron Borda y Churata cuando se embarcaron en ese trabajo demoledor que recién hoy día podemos asumir como expresión de una vanguardia andina.
} 
resuelta mediante alianzas que permitían la asimilación de lo ajeno en términos de reciprocidad y sacralidad. Esto explica por qué las huacas mayores del panteón de Huarochirí son dos hermanos culturalmente gestionados: Chaupi Ñamca, huaca femenina local, y Paria Caca, huaca masculina de origen extranjero. Mientras Chaupi Ñamca (identificada con la tierra y el río) garantiza la continuidad cultural del grupo Checa originario de Huarochirí, su hermano cosmogónico Paria Caca es originalmente un invasor. Surgió primero en forma de cinco huevos que se convirtieron en cinco halcones que a su vez se convirtieron en personas. En sus múltiples personificaciones, Paria Caca inició un proceso migratorio que culminó con la ocupación del territorio de Huarochirí por parte del grupo Yauyo. Su presencia quedó simbolizada en la gran montaña que lleva su nombre, y su culto (inseparable del de Chaupi Ñamca) estuvo destinado a garantizar la unidad política y cultural de los distintos grupos que con el tiempo quedaron asentados en Huarochirí.

Estas alianzas entre grupos locales y grupos invasores llevaron a Arguedas a percibir, en toda su perturbación y belleza, los modos andinos de explicar el mundo y de instalarse a vivir en él. La eficacia con que se resolvían situaciones tan complejas como las expansiones y migraciones de los grupos preincaicos que ocuparon el territorio de Huarochirí le indicaba cuán inadecuados y violentos eran los modos modernos (e incluso académicos) de entender procesos similares en Chimbote. Y aun cuando hay en Arguedas un deseo por legitimar la teorización académica que por esos mismos años proponía Ángel Rama a través del concepto de transculturación, es evidente que esa teorización estaba desprovista de lenguaje para dialogar con los modos de ser de la sensibilidad andina. También prometedora pero desprovista de viabilidad era esa "gran esperanza” que ofrecía por esos mismos años la teología de la liberación. Arguedas se abrazó a ella, pero intuyendo que se abrazaba a un deseo, a una esperanza que no alcanzaba para conjurar la esterilidad de su escritura: “ ¿Es mucho menos lo que sabemos que la gran esperanza que sentimos, Gustavo? ¿Puedes decirlo tú, el teólogo del Dios liberador, que llegaste a visitarme aquí, a Lorena 1275, donde estuvimos tan contentos a pesar de que yo en esos días ya no escribía nada?” (El zorro 269). Otro detalle que tuvo que haber calado hondo en Arguedas es que los relatos de Huarochirí ofrecían una visión desde la periferia del mundo andino. No era la centralidad del Cusco la que hablaba en este texto, sino la religiosidad chamánica y porfiadamente local de Huarochirí, que ni siquiera después de la ocupación incaica suplantó el culto a Paria Caca y Chaupi Ñamca por el panandino a Wiracocha. Incluso geográficamente Huarochirí representaba un sitio distintivo, situado entre la costa y la sierra. En esa periferia andina se encontraron y dialogaron por primera vez el zorro de arriba y el zorro de abajo. No es pues sorprendente que sus próximos encuentros se produzcan en otro espacio de periferia, migraciones y transculturaciones: el Chimbote de los años sesenta. Más aún, en el “¿Último diario?” Arguedas confiesa que al embarcarse en la escritura de su novela pretendía dar a conocer esas realidades y símbolos que había visto a través de los ojos de los zorros de Huarochirí, pero el proyecto quedó trunco ante la imposibilidad de transmitir a la palabra la desmesurada materia de la que están hechas las cosas andinas, pero también ante la imposibilidad de que las periferias y sus modos de conocimiento tuvieran alguna viabilidad transformadora en el Perú, donde conflictivamente coexisten “todas las naturalezas del mundo” (270). 
En este precipicio de disfuncionalidad y acabamiento de la episteme andina se da uno de los momentos de mayor contacto entre Arguedas y Vallejo; por eso es tan conmovedor leer, ya en una de sus últimas frases, que "Vallejo era el principio y el fin" (270). Desde ese sitio sin retorno Arguedas fue vislumbrando las nuevas problemáticas que surgirán en los Andes a raíz del impacto de la cultura industrial en sociedades semimodernas y semicoloniales:

...en nuestros días presenciamos cómo el impacto de la cultura industrial, especialmente
en su versión norteamericana, está golpeando duramente las raíces hispánicas e indígenas
de nuestra tradición y las está desvalorizando. Hay una especie de rendimiento ante las
estructuras de acero y cemento, una rendición de tipo incondicional y aun agresivo. La
gente, de la Capital y de las Provincias, ha sustituido peligrosamente sus antiguos ideales,
basados en la tradición hispanoindia, por los símbolos y los valores de la cultura de tipo
urbano yanki. La movilidad social está orientada hacia esos fines. Todo esto parece
demostrarnos que nuestra tradición no es muy firme, y creo que no lo es porque los dos
pueblos en los que se fundaban han sido o están siendo históricamente rebasados.
(Arguedas, Antología... 46)

La aceleración modernizadora con que la cultura industrial se imponía en el Perú, exigiendo de sus habitantes (indios o no) un rápido acomodo a costumbres y comportamientos nuevos, empujó al autor de los zorros a pensar al Perú ya no desde paradigmas exclusivamente andinos, sino desde una posición hispanoindia marcadamente apocalíptica. El diagnóstico del último Arguedas es que ambas culturas, la hispana y la andina, estaban siendo históricamente rebasadas. Esta visión, que en su momento llevó al límite una situación personal ya de principio insoportable, con el correr de los años permite vincular a Arguedas con escrituras no necesariamente andinas pero proyectadas sobre las mismas desolaciones, como la de José Emilio Pacheco, por ejemplo. ¿Acaso no resulta sorprendente que la obra de Arguedas comparta con la de Pacheco una similar percepción del "desastre" que trae consigo el tiempo histórico de la modernidad? ¿Acaso en las páginas arguedianas no laten las mismas preguntas y las mismas sospechas que tan agudamente perturban la poesía de Pacheco sin realmente encontrar caminos que las resuelvan? Basta poner la mirada en cualquiera de sus libros para palpar cercanías con Arguedas:

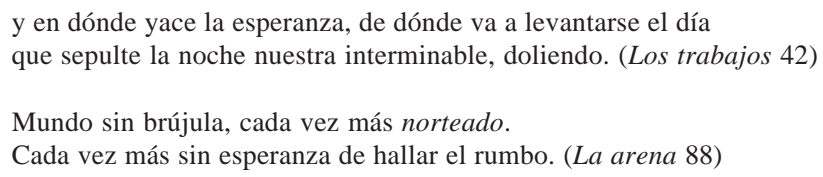

Escritura del desastre la de Arguedas, y por eso mismo escritura que estando porfiadamente arraigada en lo andino, suscita reflexiones de alcances imprevisibles. Más allá de cualquier localismo, el peso de lo andino que gobierna la palabra de Arguedas crea contextos de reflexión en torno a los destinos del pensamiento crítico latinoamericano. Cabe aquí mencionar la capacidad de la obra arguediana para dialogar con ese diagnóstico 
que Octavio Paz hiciera de la poesía y que puede resumirse en un llamado a oír voces y realidades enterradas por la modernidad. Con anterioridad al diagnóstico de Paz, Arguedas había entendido la urgencia de que el discurso poético articule un nuevo pensamiento político en el Perú. Entendió también que para ello hacía falta oír esas realidades enterradas, poco disponibles al ojo común, que Paz denomina en abstracto la otra voz pero que en Arguedas encuentran forma y sentido en las culturas y epistemologías andinas, y en sus historias de marginalización. Incluso ese diálogo que Paz planteó (pero no abordó) entre poesía, pensamiento político y filosófico, queda en la obra de Arguedas plenamente desarrollado una vez que entra en consideración la episteme andina y sus (im)posibilidades de gestionar sobrevivencias dignas en la ya inevitable maquinaria civilizatoria.

Esto lleva a pensar que la última chispa que Arguedas supo encender no fueron esos balazos que se escucharon en la Universidad Agraria, sino esa reflexión en torno a las (im)posibilidades de gestión que podrían llegar a tener en el Perú (pero no sólo en él) lógicas culturales y racionalidades distintas a las que proponen los intereses metropolitanos. Con lucidez cegadora Arguedas comprendió que en el Perú de los años sesenta esas racionalidades hablaban un idioma cultural distinto, y que iba a ser imposible esperar que su época, cooptada ya por las culturas de la industrialización, legitimara la perturbadora presencia de otra gramática en el horizonte de lo posible. Sus zorros, criaturas antiguas llamadas a hilvanar esa gramática para nosotros, no pueden realmente intervenir, la dejan, por tanto, callada, deshilvanada, expuesta al impacto de la cultura industrial.

JAIME SAENZ O DE CÓMO HILVANAR UNA GRAMÁTICA CULTURAL QUE HA PERDIDO ESPESOR, QUE SE HA VACIADO, QUE NO DA SOMBRA SIQUIERA...

Seguramente hay muchas maneras de ahondar en las rutas abiertas por Vallejo y Arguedas. En esta sección opto por un cambio radical de perspectiva al proponer la discusión ya no desde los Andes peruanos y desde la cultura quechua, sino desde los Andes bolivianos y desde el mundo aymara, que pese a su extraordinaria vitalidad y actual protagonismo histórico, ha entrado poco al debate sobre lo andino y, en general, al discurso crítico contemporáneo. Predomina todavía la idea virreinal de que el mundo quechua centraliza la historia cultural en los Andes. Y sin embargo, como veremos más adelante, ha sido desde la territorialidad aymara desde donde se ha reconfigurado el conflicto andino, y también desde donde se ha dialogado intensamente con las provocaciones epistemológicas de Vallejo y Arguedas. Una serie de circunstancias históricas y culturales han permitido este protagonismo indígena en los Andes bolivianos. En primer lugar hay que advertir que a diferencia del Perú, donde la hegemonía limeña logró, desde los primeros años de la república, desentender al país de las historias andinas, en Bolivia ni La Paz ni Chuquisaca (capital ejecutiva y capital histórica respectivamente) pudieron desembarazarse de los indios y de la geografía que habitaban. No importó cuán enamoradas de España y del castellano estuvieran las élites criollas que desde los primeros años de la independencia se sintieron llamadas a fundar la literatura boliviana: prevaleció la fuerza de las montañas que circundaban sus ciudades y dotaban a los habitantes de referentes cuya hermenéutica desconocían, pero que difícilmente podían ignorar. Como observó Blanca Wiethüchter, más allá del desprecio o vergüenza que sentían por los indios, ¿cómo ignorar 
su amenazadora proximidad o la aplastadora presencia de sus símbolos? ¿Cómo resistir la belleza de los cerros que vigilaban las ciudades? Porfiadamente, sin embargo, el país blanco y mestizo luchó durante todo el siglo xix y parte del xx por impedir el ingreso de los indios a la república de la cultura y al ejercicio de la política. Wiethüchter supo exponer estos dilemas desde perspectivas pocas veces frecuentadas por el lenguaje de la crítica:

En los Andes se vive nomás una geografía poblada de nombres cuyo poder de invocación desconocemos y que por lo mismo nos obligan a acudir a yatiris para ch'allar, para desalojar awichas de lugares de los que no quieren irse, etc. Es cierto, podemos poseer, violentar, despojar, arruinar a los indígenas, pero no arrancarles el secreto poder del nombre de la tierra de adentro, y por tanto, el poder de invocar y conjurar. Porque los indígenas, aquí, en los Andes, son los dueños de los nombres, por lo tanto de los lugares, por lo tanto de la magia. ¿Quién puede enfrentar semejante poder? La imposibilidad de despojar el espacio de esa otra voz que es sagrada, torna el trabajo textual altamente conflictivo, más si se ignora ese diccionario que otorga humedad, llama, oxígeno y raíz a las palabras. Todo ello instaura una distancia respecto del paisaje que se habita, de lo cotidiano que pide intermediarios indígenas para conocer... para curar, para conjurar. Nos falta la gramática andina. (61; énfasis mío)

¿Acaso no era precisamente la falta de una gramática andina la herida que obsesionó a Vallejo y Arguedas? Vallejo vivió esa falta como insuperable; su tiempo histórico no le proporcionó formas de devolverle espesor al vacío. Arguedas, que también vivió la falta como herida, pudo acceder a la erótica del espacio andino y escuchar esa otra racionalidad que emergía de su geografía y de sus grandes relatos, pero el poder de invocación que de allí emanaba, junto a la virtual inviabilidad de un proyecto de reconstitución social y cultural en el Perú, lo paralizaron. Esa parálisis, sin embargo, fue productiva, porque la inconclusividad a que llegó su obra se produjo en medio de hervores de fertilidad.

Paradójicamente, no fue en los Andes peruanos sino en los bolivianos donde esos hervores alcanzaron expresión y protagonismo histórico, porque mientras en el país de Arguedas “el indio ya no es más un referente para entender la realidad peruana” y hoy por hoy “no refiere más a la mayoría” (Cecilia Méndez, 41), en Bolivia se ha instalado como mayoría histórica y actor político con capacidad no sólo de reorientar el curso de la literatura, sino también de desestabilizar la estructura del Estado republicano y de la conciencia mestiza. ${ }^{8}$ Una serie de factores histórico-culturales han permitido esta diferencia. En primer lugar, el hecho de que en la literatura boliviana ha habido escritores y proyectos críticos que le han dado continuidad a la vanguardia andina y han hecho de Borda y Churata verdaderos paradigmas anticanónicos de creatividad, cosa que no sucedió en el Perú, donde la obra de Borda no se conoce y la de Churata quedó, para la gran mayoría de los peruanos, enterrada como extravagante. A esto, se suma el hecho de que en Bolivia, a diferencia del Perú, se ha producido la emergencia de una vigorosa intelectualidad

${ }^{8}$ Prueba de ello fueron los levantamientos indígenas del año 2000; la formación de partidos políticos de dirigencia indígena como el MAS (Movimiento al Socialismo) y el MIP (Movimiento Indio Pachacuti), que en las elecciones de 2002 le disputaron votos a los partidos tradicionales; y el éxito electoral del MAS en las elecciones de 2006, que llevaron a la presidencia a Evo Morales, el primer presidente indígena de Bolivia y de América. Al respecto véase García Linera et. al., y Prada. 
andina que a lo largo de todo el siglo xx ha estado politizando sus culturas ancestrales y construyendo una conciencia política indígena con la que el Estado boliviano republicano tuvo que aprender a negociar. Consultar al respecto Rivera Cusicanqui, Reinaga y Patzi.

Tomando en cuenta estas características de la historia andina en Bolivia y sin perder de vista las rutas abiertas por Vallejo y Arguedas, quisiera ahora enfocar el análisis en un escritor que en mi opinión fue el único que, en la vena de Borda y Churata, llegó a hilvanar una gramática cultural distinta y con ella a insertar lógicas andinas en el horizonte cultural de todo un país: Jaime Saenz (1921-1986).

La obra de Saenz transita prácticamente todos los terrenos del arte (poesía, narrativa, artes plásticas, teatro y ensayo) y está marcada por la sospecha de que el ser humano es un eterno y perdido caminante sobre la tierra. Reticente a todo tipo de encasillamientos y siempre advirtiendo que la "incontenible y devastadora avalancha del progreso" no puede sino estar "al servicio de la expansión mercantil y en función del embrutecimiento colectivo” (Introducción 7-8), Saenz pertenece a una generación que en su opinión “está frustrada porque se ha rendido ante la pequeña tentación del vivir cómodo y ha dejado de hacer lo que tenía que hacer” (López Muñoz). Palabras ciertamente sobrecogedoras, que en más de un sentido recuerdan al Vallejo de 1927, cuando iracundo levantaba su voz para acusar a su generación de “impotente para crear o realizar un espíritu propio”, subrayando que "hoy, como ayer, los escritores de América practican una literatura prestada, que les va trágicamente mal” (xv).

Como en muchos de los poemas de Vallejo, en la obra de Saenz el conflicto andino no está abordado de modo explícito; hasta podría pensarse que no hay en ella una legítima preocupación por lo andino. Y sin embargo nadie como Saenz supo captar en un poema o en un relato el ritmo interno de la marginalidad andina en Bolivia. Sin necesariamente coincidir con Vallejo o Arguedas (de hecho no hay en su obra una sola referencia a Arguedas; a Vallejo en cambio le rinde culto porque admira esa capacidad suya para no huir del dolor), Saenz entendió que el problema de los países andinos era que todavía no se había producido en ellos una conciencia acerca de cómo habitarlos. En su opinión, las influencias del mundo actual, con sus múltiples ofertas de desarrollo y tecnología,

encuentran natural resistencia en estas alturas, pues dichas influencias aunque en algunos casos reportan beneficios, las más de las veces resultan nocivas, con normas, adelantos, divisas y aun costumbres que, decididamente, no concuerdan -por así decirlo- con nuestro modo de estar, y mucho menos con nuestro modo de ser. (Imágenes 10-1; énfasis mío)

Asombra la frescura, la simpleza con que en unas pocas palabras queda expuesta la problemática andina: en los Andes hay modos de ser y modos de estar que no se entienden con la modernidad. O dicho de otra manera, la modernidad no llega a entender los modos de ser y estar andinos. Arguedas había enfrentado esos modos de ser y estar en su encuentro con los relatos de Huarochirí, pero el encuentro había sido cegador. En Saenz la percepción de la razón andina es también cegadora, pero no produce herida. La terrible inmensidad con que en los Andes se muestra la geografía lleva a Saenz a adquirir conciencia de que "una montaña no es meramente una montaña. Una montaña, y en particular el Illimani, constituye una acumulación de energía” (Felipe 174). En su caso, 
el encuentro con esa energía más que maniatar la escritura la hace posible, porque permite ver lo que de otra manera no se vería, por ejemplo las profundas paradojas que la modernidad inscribe en las urbes andinas:

Dando por sentado que la ciudad de La Paz tiene una doble fisonomía, y admitido que mientras una se exterioriza la otra se oculta, hemos querido dirigir nuestra atención a esta última. Pues en efecto, lo que aquí interesa es la interioridad y el contenido, el espíritu que mora en lo profundo y que se manifiesta en cada calle y en cada habitante, y en el que seguramente habrá de encontrarse la clave para vislumbrar el enorme enigma que constituye la ciudad que se esconde a nuestros ojos. (Imágenes 9)

Uno a uno los libros de Saenz van revelando las inconsistencias de La Paz (y por extensión de cualquier ciudad creada bajo imperativos coloniales y orientada por modelos civilizatorios) en su exterioridad semimoderna. En su enigma interior, en cambio, la ciudad va conformando líneas de fuerza cuyos referentes son siempre andinos. Sometida a este tratamiento, La Paz surge como una territorialidad que en verdad pertenece a los aymaras, que con sus modos de ser y de estar se mofan de aquella otra ciudad, responsable de su envilecimiento y miseria. Ellos, los aymaras residentes en La Paz, son los únicos que hacen y deshacen de la ciudad por el simple hecho de habitarla en su interioridad. Acto temerario sin duda, porque arroja sobre ellos el estigma de la marginalidad, que condena sus vidas a existencias miserables. Durante muchos años Saenz se dedicó a la elaboración de una teoría poética que diera cuenta de la vida y obra de estas marginalidades, cuya expresión más acabada era la existencia de los aparapitas paceños (aymaras residentes en La Paz que se ganan la vida cargando bultos de otros). Este proyecto de darle forma y articulación literaria a la marginalidad misma está expresado en un célebre artículo publicado en 1968 con el título de "El aparapita de La Paz”, y también en las páginas de Imágenes paceñas y Felipe Delgado, ambos textos publicados en 1979.

Vale la pena observar que con anterioridad a Sáenz, la existencia del aparapita había sido ignorada por artistas e intelectuales, que siguiendo la fuerza de la costumbre lo percibían como un parásito social opuesto a cualquier forma de vida moderna, o simplemente como un indio alcoholizado sin derecho a ciudadanía. La excepción a esta norma funesta fue el escritor y artista plástico Arturo Borda (1883-1953), el loco que se atrevió a vivir enamorado del Illimani y a desafiar el pongueaje intelectual de su época con una obra que dislocó la enclenque armonía letrada de la intelectualidad boliviana y sentó las bases de una vanguardia andina en Bolivia. ${ }^{9}$ En diálogo profundo con Borda, que de

${ }^{9}$ La obra de Arturo Borda está cruzada por el dibujo, la pintura, la literatura y algunas incursiones en el cine. En base a información proporcionada por el propio autor sabemos que pintó y dibujó intensamente (alrededor de dos mil cuadros y mil dibujos en su mayoría desaparecidos), fundó periódicos y revistas (Albatroz, El Ferroviario, Inti, etc.), actuó en dos películas hoy día consideradas clásicos del cine mudo boliviano. (Wara wara, 1930 y Hacia la Gloria, 1932), fue fundador y Secretario General de la Gran Confederación Obrera Boliviana del Trabajo, gestionó las primeras leyes sociales en Bolivia y vivió constantemente rechazado por un medio que le era contrario y al que se propuso demoler. En 1901 Borda inició la escritura de lo que sería su único libro: El loco, póstumamente publicado en 1966 en tres volúmenes. En palabras del propio Borda, en este libro "lo 
muchas maneras fue un maestro, y en contraste con la opinión estereotipada de la época, Saenz percibió al aparapita y su desgarrada, parchada vestimenta (resultado del increíble estado al que llega la ropa cuando es sometida a innumerables remiendos), como una legítima representación de la ciudad de La Paz, también resultado de innumerables remiendos y parches. Hay que anotar que esta percepción del aparapita tuvo su inspiración en un monumental óleo de Arturo Borda titulado El Yatiri, que muestra en primer plano a este personaje aymara luciendo un saco de iguales características.

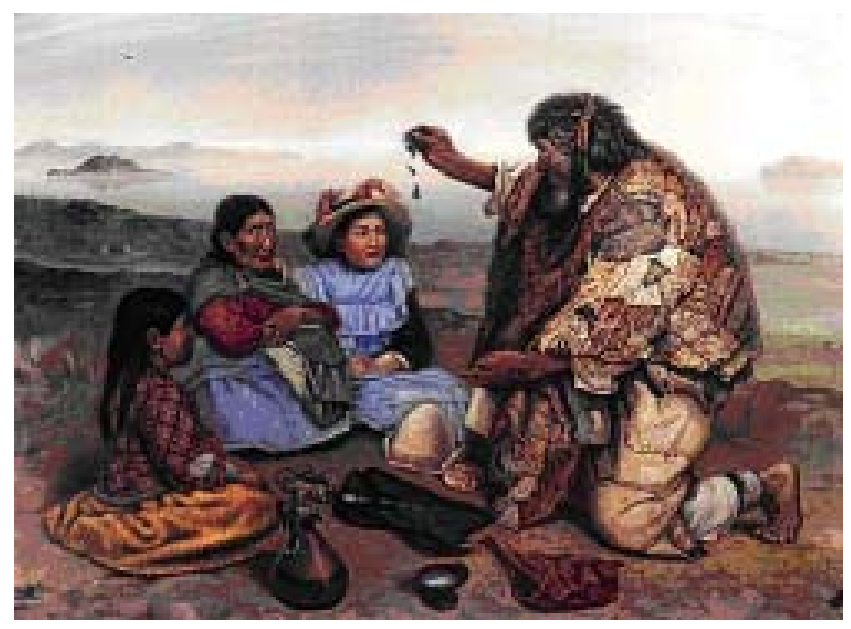

Arturo Borda: El Yatiri (La Paz, 1918) Óleo sobre lienzo. Colección particular, La Paz.

Con el correr de los años y una vez madurado en Bolivia un sólido pensamiento crítico, esta representación no sólo se convirtió “en la mejor imagen que tenemos como país” (Wiethüchter y Paz Soldán 6), sino que además le creó alternativas originales a conceptos teóricos que, como el mestizaje, la hibridez y la heterogeneidad, permean el espacio de reflexión sobre los Andes, aun cuando carecen de propuestas que otorguen protagonismo a los actores sociales que sólo teóricamente entran en discusión. Nada más adecuado para dialogar con el óleo de Borda que un parlamento de Felipe Delgado (personaje narrativo saenciano) cuando descubre la realidad de un saco de aparapita:

brutal del realismo se diluye en nieblas crepusculares o Auroras boreales en tinieblas. Y en todo desconcierta el contraste de las armonías que quedan, zumbando en el recuerdo" ("Autobiografía” 10). En palabras de la crítica más reciente, El loco "no pertenece a ningún género y se resiste ferozmente a dejarse encerrar en un recuadro. Lo que pretende es una modificación violenta de la historia, una desobediencia a la norma, que proyecta un pensamiento si se quiere descolonizado”. (Wiethüchter y Paz Soldán 98). 
El espectáculo que tenía a la vista resultaba alucinante por completo... los remiendos que en ese momento se hallaba contemplando en el saco del aparapita, parecían haber sido concebidos en una pesadilla de la vida real. ¿Cómo era posible que sólo ahora se hubiese fijado en ellos...? Y tenía ante sus ojos remiendos de todo tamaño y de toda forma, los había de las más variadas telas, pero sin embargo, el color era uno solo, pues la diversidad de colores había sin duda experimentado innumerables mutaciones hasta adquirir el color del tiempo, que era uno solo... Con una mezcla de temor y de repulsión, miraba por momentos en este conjunto de remiendos un tejido vivo, y se imaginaba que éste debía ser sin duda el aspecto ofrecido por el cuerpo que se pudre en el sepulcro. (142-3)

Rescatar al personaje y percibir su vestimenta como un tejido vivo que interpreta, entre otras cosas, la realidad del país, fue un acontecimiento que reorientó el rumbo del imaginario cultural en Bolivia. Por primera vez la voz de un poeta tenía la capacidad de cautivar la sensibilidad de toda una época con sólo haber poetizado los rincones más oscuros y siniestros de la modernidad andina. De modo verdaderamente extraño, sin precedentes, Saenz supo entregarle al país andino una reflexión poética sobre su propio ser sin transitar por las rutas del indigenismo o de la antropología. Forjó para ello un lenguaje de fuerte autonomía referencial, pero que a diferencia de los lenguajes autorreferenciales, desarraigados y carentes de historia, captaba el ritmo interno de las culturas andinas y porfiadamente se arraigaba en sus modos de ser y de estar. Y aún cuando los personajes saencianos, sean éstos líricos o narrativos, están siempre amenazados de extinción (algunos buscan la muerte, otros simplemente desaparecen), sus vidas marginales y las memorias que nos dejan hilvanan para nosotros una poderosa gramática cultural para seguir pensando y para seguir viviendo en los Andes. Esa gramática es, al fin y al cabo, la única posibilidad de gestión que tienen los sujetos andinos, y se la debemos tanto a quienes como Vallejo, Arguedas y Saenz, la poetizaron, como a las multitudes aymaras y quechuas que desde la soledad indígena la pelean día a día con las estrategias políticas de la modernidad.

¿No es acaso significativo que en los años que siguieron a la obra saenciana el país se embarazara de los indios, llegando a registrarse acontecimientos históricos impensables hace apenas veinticinco años, como el surgimiento de un presidente aymara, la formación de un Sindicato de aparapitas Jaime Saenz, o la viabilización de proyectos indígenas descolonizadores? Los indios, paradójicamente, se desembarazaron del país y de los q'aras que durante tantos años habían impedido su ingreso a la república. Literalmente se "rebelaron” y provocaron pánico en la población mestizo-criolla. El protagonismo andino, tan ansiado por Vallejo y Arguedas, tuvo finalmente su moderno momento histórico, su "septiembre indígena" como se recuerda al levantamiento aymara del año 2000, en el que más de cincuenta mil indios liderados por un Mallku aymara inauguraron el siglo xxı poniendo al Estado boliviano y a la configuración republicana frente a la crisis más profunda de su historia. En una entrevista realizada poco tiempo después del levantamiento, Felipe Quispe, el Mallku, explica la poética de la rebelión:

Hemos utilizado nuestra propia ideología, por qué no decir el pachacutismo divino que viene de abajo a arriba... Estamos en el tiempo del Pachakuti, las Wak'as van a volver a hablar, las piedras van a revelar cosas insospechadas. Entonces, los ríos volverán a 
cantar. Todo lo que habíamos tenido hemos utilizado y eso nos ha servido de gran manera con lo cual hemos tenido que rebelarnos en el septiembre indígena. (García Linera 170)

Seis años más tarde, el 22 de enero de 2006, 473 años después de la inmolación del Inca Atahuallpa en Cajamarca, un líder indígena volvió a ceñir el bastón de mando andino.Y aun cuando es incierto el cauce que estos hechos puedan tener en el futuro, resulta evidente el cambio de signo que se ha operado en la historia andina: estamos en tiempos de Pachakuti y cualquier negociación tendrá que darse en diálogo con la razón indígena. ¿Estará la conciencia criollo-mestiza preparada para este cambio de signo? ¿Podrá la razón indígena insertarse en un orden históricamente antagónico y poco dispuesto a devolverle espacios de existencia? ¿Podrá la cultura imaginada de la globalización convivir con historias, memorias y temporalidades que le disputan legitimidad al horizonte neoliberal?

\section{BibliografíA}

Antezana, Luis. “Felipe Delgado”. Ensayos y lecturas. La Paz: Altiplano. 1986. 333-54. "Hacer y cuidar”. Ensayos y lecturas. La Paz: Altiplano. 1986. 231-64.

Arguedas, José María. El zorro de arriba y el zorro de abajo. Buenos Aires: Losada, 1971. "Para una antología de la tradición en el Perú”. Antología de la tradición, ofrenda

a la ciudad de Lima. César Revoredo Martínez, ed. Lima: Mejía Baca, 1962. , trad. Dioses y hombres de Huarochirí: Narración quechua recogida por Francisco de Avila [¿1598?]. Pierre Duviols, ed. Lima: Instituto Francés de Estudios Andinos; Instituto de Estudios Peruanos, 1966.

Borda, Arturo. El loco. 3 vols. La Paz: Alcaldía de La Paz; Biblioteca Paceña, 1966. “Autobiografía” [1962] La Mariposa Mundial 2 (La Paz, 2000): 9-12.

Bourdieu, Pierre. El campo político. Emmanuel Capdepont et al., trads. La Paz: Plural, 2001.

Bosshard, Marco Thomas. Hacia una estética de la vanguardia andina. Gamaliel Churata entre el indigenismo y el surrealismo. Berlín: Wissenschaftlicher Verlag [en prensa].

Castro-Klaren, Sara. “Como chancho, cuando piensa: el afecto cognitivo en Arguedas y el con-vertir animal”. Elizabeth Monasterios y Martha Nandorfy, eds. Revista Canadiense de Estudios Hispánicos XXVI/1-2 (2002): 25-39.

Churata, Gamaliel. El pez de oro, retablos de laykhakuy. La Paz: Canata, 1957.

García Linera, Álvaro, et al., eds. Tiempos de rebelión. La Paz: Muela del Diablo, 2001.

González Fernández, Gissela y Juan Carlos Ríos Moreno. El proceso americano. Evolución de una estética en los artículos de Gamaliel Chuarta. [inédito] Lima: Universidad Nacional Mayor de San Marcos, 1996.

Huamán, Miguel Ángel. Fronteras de la escritura. Discurso y utopía en Churata. Lima: Horizonte, 1994.

López Muñoz, Gonzalo. “Una entrevista con Jaime Sáenz”. [1965] Presencia Literaria 1 (1986). 
Mariátegui, José Carlos. Siete ensayos de interpretación de la realidad peruana. [1928] 3 ed. La Habana: Casa de las Américas, 1975.

Melis, Antonio. “El aporte de José Carlos Mariátegui a la fundación de la historia literaria andina”. Memorias. JALLA La Paz. La Paz: Plural, 1995. 499-507.

Méndez, Cecilia. "República sin indios: La comunidad imaginada del Perú”. Henrique Urbano, ed. Tradición y modernidad en los Andes. 2 ed. Cusco: Centro Bartolomé de Las Casas, 1997. 15-41.

Monasterios, Elizabeth. Dilemas de la poesía de fin de siglo. José Emilio Pacheco y Jaime Saenz. La Paz: Plural, 2001.

Montale, Eugenio. “Is poetry still possible?” [1975] Les prix Nobel en 1975. Stockholm: Imprimerie Royale P.A. Norstedt \& Doner, 1976. 214-20.

Pacheco, José Emilio. La arena errante. México: Era, 1999.

Tarde o temprano. [1980] 2 ed. México: FCE, 1986.

Los trabajos del mar. México: Era, 1983.

“Notas sobre la otra vanguardia”. Revista Iberoamericana 106-7 (1979): 327-34.

Patzi Paco, Félix. Sistema comunal. Una propuesta alternative al sistema liberal. La Paz: CEA, 2004.

Paz, Octavio. La otra voz. Poesía y fin de siglo. Barcelona: Seix Barral, 1990.

Pantigoso, Manuel. El ultraorbicismo en el pensamiento de Gamaliel Churata. Lima: Universidad Ricardo Palma, 1999.

Platt, Tristan. "Entre Ch'axwa y Muxsa. Para una historia del pensamiento político aymara”. Tres reflexiones sobre el pensamiento andino. Thérèse Bouysse-Cassagne et al., eds. La Paz: HISBOL, 1987. 61-132.

Prada Alcoreza, Raúl. Largo Octubre. La Paz: Plural Editores, 2004.

Rama, Ángel. Transculturación narrativa en América Latina. México: Siglo XXI, 1982.

Rivera Cusicanqui, Silvia. Oprimidos pero no vencidos. Luchas del campesinado aymara y qhechwa 1900-1980. La Paz: Hisbol-CSUTCP, 1983.

Reinaga, Fausto. Indianidad. La Paz: Imprentas Unidas S.A., 1978.

Rowe, William. Hacia una poética radical. Rosario: Beatriz Viterbo, 1996.

Saenz, Jaime. Felipe Delgado. La Paz: Difusión, 1980.

Imágenes paceñas. Lugares y personas de la ciudad. La Paz: Difusión, 1979.

Introducción. Asistir al tiempo. De Blanca Wiethüchter. La Paz: Imprentas Unidas, 1975. 7-12.

“El aparapita de La Paz”. Mundo Nuevo (ago-set 1968): 26-7.

Salomon, Frank. “Introduction”. The Huarochirí Manuscript: A Testament of Ancient and Colonial Andean Religion. Austin: University of Texas Press, 1991. 1-38.

Vallejo, César. Obra poética completa. Lima: Moncloa, 1968. Obra poética completa. La Habana: Casa de las Américas, 1993.

Wiethüchter, Blanca y Alba María Paz Soldán, eds. Hacia una historia crítica de la literatura boliviana. La Paz: Plural, 2002.

Zevallos, Ulises Juan. Indigenismo y nación. Los retos de la representación de la subalternidad aymara y quechua en el Boletín Titikaka (1926-1930). Lima: IFEA, 2002. 